\title{
Development and Application of Lipid Nanotechnology on Infectious Diseases of CNS- Current Scenario
}

\author{
Swarupanjali Padhi',*, Rupa Mazumder ${ }^{1}$, Shradha Bisth $^{2}$ \\ ${ }^{1}$ Pharmacy Institute, Noida Institute of Engineering and Technology, Greater Noida, Gautam Buddha Nagar, Uttar Pradesh, INDIA. \\ ${ }^{2}$ Department of Pharmacy, Sardar Bhagwan Singh Post Graduate Institute of Biomedical Science and Research, Balawala, Dehradun, \\ Uttarakhand, INDIA.
}

\begin{abstract}
Background: This is an era of inventive technology illuminating fundamental mechanisms of diseases and fabricating drug molecules according to prerequisite condition, but it is still a challenge to target infectious diseases specially in CNS due to various restrictions of drug delivery to the brain and drawbacks of various conventional antimicrobial agents. These are prone to development of multiple drug resistances as sufficient amount of drug cannot reach to the site of infection. Materials and Methods: This review summarizes the problems associated with the amount of drug delivered to CNS and the emergence of new tools like lipid nanoparticles to deal with the current challenges in treating infectious diseases of CNS. Results: This article discusses the anatomical and physiological barriers of CNS and development of various drug delivery system, specially the development of lipid nanoparticles including solid lipid nanoparticles, nanostructured lipid carriers, lipid drug conjugated nanoparticles to address the challenges. Conclusion: This article is an extensive review on current status of drug therapy of infectious diseases of CNS. Lipid nanoparticles like SLN and NLCs have proven to be effective tools for improved drug delivery to CNS and PNS.
\end{abstract}

Key words: Multiple drug resistance, Solid lipid nanoparticles, Nanostructured lipid carriers, Lipid drug conjugated nanoparticles, CNS, Blood-brain barrier.

\section{INTRODUCTION}

The futile treatment of CNS disorders by most of the neurotherapeutics can be due to their ineffective drug delivery. Although brain has relatively high blood flow yet drug delivery to the brain is most challenging because of the two physiological barriers i.e., Blood-Brain Barrier (BBB) and BloodCerebrospinal Fluid Barrier (BCFB). BBB and $\mathrm{BCFB}$ separates the brain from its blood supply controlling the transport of compounds and this is the reason why most of the brain or CNS associated diseases remain untreated by effective therapies. Contemporary approaches like ligand conjugation and nanotechnology are used to target the barriers of CNS by means of various transport pathways and various surface fabrication. ${ }^{1}$

Infectious diseases were the main cause of death at the juncture of $19^{\text {th }}$ and $20^{\text {th }}$ century. $^{2}$ The advent of antibiotics led to a decrease in morbidity and mortality in the last century. However, of late microbe developing resistance to antibiotics is posing a serious problem in health administration. ${ }^{3,4}$ The cause of brain infection are viruses, bacteria, fungi or occasionally, protozoa or parasites listed in Table $1 .^{5-19}$ Another group of brain disorders, called spongiform encephalopathies, are caused by abnormal substances called prions. ${ }^{5,6}$

\section{Challenges Associated with Infectious Disease of Brain}

There can be possibly three main causes which makes the management of infectious disease difficult:

\section{Delay in Clinical Diagnosis}

In case of patients where the classic symptom may be minimal or absent.
Submission Date: 14-08-2018; Revision Date: 28-12-2018; Accepted Date: 27-03-2019

DOI: 10.5530/ijper.53.3.69 Correspondence: Mrs. Swarupanjali Padhi, Assistant Professor, Institute of Pharmacy, Noida Institute of Engineering and Technology, Greater Noida, Gautam Buddha Nagar, Uttar Pradesh - 201306, INDIA Phone: +91-7011164903 E-mail: swppadhi@gmail. com

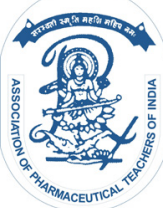

www.ijper.org 


\begin{tabular}{|c|c|c|c|}
\hline S. No & $\begin{array}{c}\text { Causative } \\
\text { micro-organism }\end{array}$ & Disease & Reference \\
\hline 1 & Fungal & $\begin{array}{ll}\text { - } & \text { Cryptococcal meningitis } \\
\text { - } & \text { Brain abscess }\end{array}$ & $\begin{array}{l}7 \\
8\end{array}$ \\
\hline 2. & Protozoal & $\begin{array}{ll}\text { - } & \text { Toxoplasmosis } \\
\text { - } & \text { Malaria } \\
\text { - } & \text { Primary amoebic meningoencephalitis }\end{array}$ & $\begin{array}{c}9 \\
10 \\
11\end{array}$ \\
\hline \multirow[t]{3}{*}{3.} & Bacterial & $\begin{array}{ll}\text { - } & \text { Tuberculosis } \\
\text { - } & \text { Leprosy } \\
\text { - } & \text { Neurosyphilis } \\
\text { - } & \text { Bacterial meningitis } \\
\text { - } & \text { Late stage Lyme disease } \\
\text { - } & \text { Brain abscess } \\
\text { - } & \text { Neuroborreliosis }\end{array}$ & $\begin{array}{c}12 \\
13 \\
14 \\
15 \\
16 \\
7 \\
17\end{array}$ \\
\hline & Viral & $\begin{array}{ll}\text { - } & \text { Viral meningitis } \\
\text { - } & \text { Eastern equine encephalitis } \\
\text { - } & \text { Japanese encephalitis } \\
\text { - } & \text { West Nile encephalitis } \\
\text { - } & \text { Herpes simplex encephalitis } \\
\text { - } & \text { Rabies } \\
\text { - } & \text { California encephalitis virus } \\
\text { - } & \text { La Cricella-zoster encephalitis } \\
\text { - } & \text { Measles encephalitis } \\
\text { - } & \text { Nipah virus encephalitis } \\
\text { - } & \text { Poliomyelitis } \\
\text { - } & \text { Slow virus infections, which include: } \\
& \text { - Subacute sclerosing panencephalitis } \\
\text { - Progressive multifocal leukoencephalopathy } \\
\text { - Acquired immunodeficiency syndrome (AIDS) }\end{array}$ & $\begin{array}{l}18 \\
19\end{array}$ \\
\hline & Prionic & $\begin{array}{ll}\text { - } & \text { Creutzfeldt-Jakob disease } \\
\text { - } & \text { Fatal familial insomnia } \\
\text { - } & \text { Gerstmann-Sträussler-Scheinker syndrome }\end{array}$ & 5,6 \\
\hline
\end{tabular}

\section{Misinterpretation of Laboratory Diagnosis}

Problem arises due to wrong diagnosis of infectious and non-infectious diseases, secondary infections and causative organism, leading to wrong treatment.

\section{Treatment}

The most challenging part is the delivery of appropriate dose and maintenance of required dose in CNS.

This review discusses various aspects of nanotechnology which will help us get success in the war against infectious disease caused in CNS. The brain, which, is a very important organ and made of soft tissues, is well protected with a skeletal system and underlining network of capillary system, which, in turn, restrict or prevent the entry of intrusive chemicals, including therapeutic agents. ${ }^{19}$

\section{Factors Preventing the Entry of Drugs into CNS}

\section{Barrier Membranes}

In CNS there are two barriers.

\section{Blood Brain Barrier}

Brain capillaries walls are composed of specialized endothelial cells that are connected to each other with tight junctions and have no fenestration. ${ }^{20,21}$ Usually micro vesicles are absent for vesicular transport. A thick basement membrane covers the endothelial cells of brain capillaries. The other components of BBB are astrocytes and pericytes. The rear part of astrocyte also covers a significant section of endothelial cell. The pericytes are engulfed in the basal membrane and covers $22 \%-33 \%$ of the endothelial membrane. The tight junction along with no fenestration, low transcytosis and paracellular diffusion of hydrophilic substance, inhibits the brain from uptake of therapeutic agents. ${ }^{22-25}$ Only those molecules whose mass is less than $150 \mathrm{Da}$ for hydrophilic compounds and mass less than 400 to 500 Da for hydrophobic compounds cross by passive diffusion through the membrane but majority of antibiotics and antitumoral molecules cannot cross the barrier membrane. ${ }^{26,27}$ 


\section{Blood Cerebrospinal Fluid Barrier}

BCFB plays an important role in regulating CNS homeostasis and transfer of material from systemic circulation and the $\mathrm{CSF}^{28}$ The Choroid Plexus (CP) is made up of capillary bed, the piamater and large number of epithelial cell. BCFB prevent the entry of endogenous substance into the brain, thus, plays an important role in preventing the entry of therapeutic agents. BCFB prevent the transport of small molecules and ions through the intercellular space of the membrane and prevent the passage of comprehensive membrane proteins between the apical and basolateral membrane of the cell. Membrane and luminal surface of brain capillary, constituents of CSF or ISF, functional groups, change on molecular and ionic surfaces or presence of charged residues of the molecules are the factors which influences the membrane permeability. Choroid plexus participates in different functional and developmental activities like movement of materials between the systemic circulation and the CSF, early stages of brain development, immune function of brain, neuronal functional maturation and regulate neuroendocrine system. Researchers has studied influence of the blood-CSF barrier role in various neurological disorders like chemical-induced neurotoxicity, aberrant brain development. ${ }^{29-31}$

\section{Efflux transport mechanism}

The efflux mechanism also helps in detoxifying system for brain. BBB pumps xenobiotics and other endogenous compounds out of the brain. Efflux pumps have vital role in the multi drug resistance of Gram-negative bacteria and provides the main hurdles in the drug discovery process. Drug-efflux transporters that are present at the blood brain barrier limit the ability of many drugs to enter the brain. These efflux systems play a vital part in drug resistant brain disorders. From Keith Poole review it is clear that formulating drugs with already present or new efflux transporter agents has to be considered to treat drug-resistant infection.

Efflux transporter expressed on the BBB belongs to ATP-Binding Cassette (ABC) gene family, which, are needed for drug distribution and elimination from brain. The ABC efflux transporter P glycoprotein which is expressed in the BBB plays an active role in transporting different lipophilic drugs out of the brain. It has been reported that apart from P-gp, other $A B C$ efflux transporters such as multi drug resistance protein (MRP) family and Breast Cancer Resistance Protein (BCRP) also impact to BBB-efflux function. ${ }^{32-34}$ Thus, $\mathrm{ABC}$ efflux transporter inhibits both endogenous and exogenous transport of substances. This reason also contributes to the limitation of accessibility of thera- peutic agents which are essential for treatment of CNS disorders. ${ }^{35}$

These multi drug resistance proteins are mostly found in gram-positive bacteria. Importance of efflux pumps in bacterial antibiotics resistance, hence, has to be considered while designing the treatment strategy. In addition to the above factors, surface activity of the molecules, its relative size and specific binding of transporter proteins, energy driven cassettes and opening and closing of ion channels due to ionic concentration are the key factors which play an important role in drug delivery. ${ }^{36,37}$

\section{Approaches to Increment the Delivery Drugs to the Affected Site}

The main challenges associated with treatment of brain had already been discussed above. The important point is how to address these problems. Confined and controlled delivery of drugs to the required site is necessary to minimize toxicity and enhance the treatment efficiency (Figure 1).

\section{Noninvasive Technique}

\section{Chemical Method}

In this approach, the drugs functionalities are changed by altering its chemical structure which, in turn, enhance their solubility and membrane penetration. ${ }^{38}$

\section{Lipophilic Analogs}

Lipid analogs are attached to the polar ends of the drug to increase the lipophilicity of the drug. Lipidization increases the permeability of the drug through BBB.

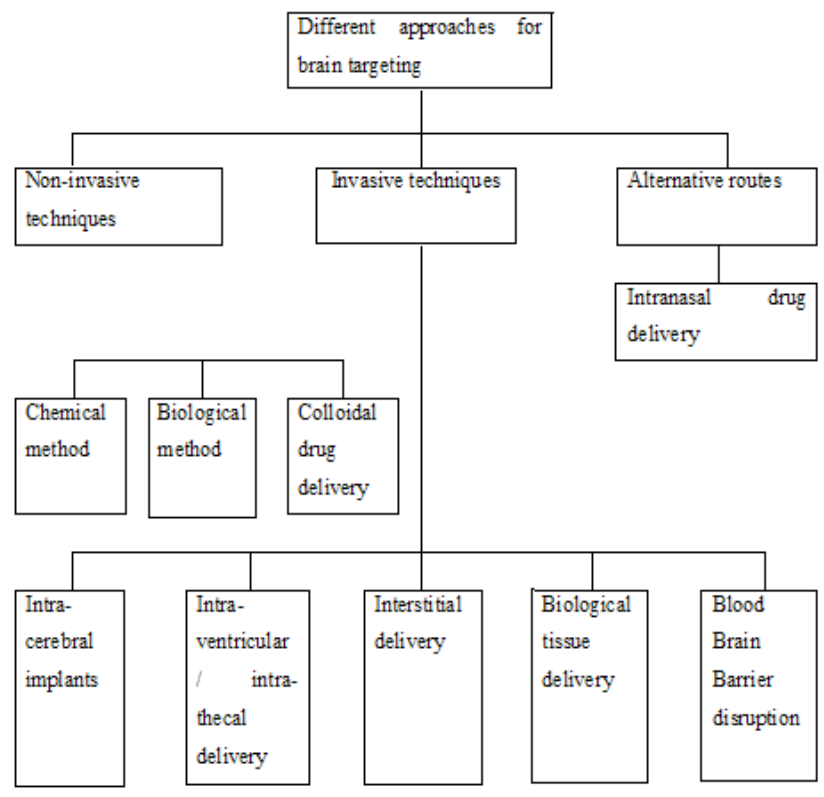

Figure 1: Different Approaches used for Treatment of Diseases in CNS. 


\section{Prodrugs}

Prodrugs are those compounds which are inactive when administered and become an active pharmacological agent after it enters into the body. With chemical modification, the prodrug method is used to make a drug more lipophilic. However, it should be taken into consideration that certain prodrug molecules and process involved in prodrug synthesis may alter the original tissue distribution, efficacy and toxicity of parent drug.

\section{Molecular Packaging}

This approach has been developed with three aims: first, improve lipophilicity to enhance passive transport, secondly, increase enzymatic stability which in turn prevent the premature degradation of the drugs, thirdly manipulation of lock-in mechanism to target the CNS. Thus, this is a promising strategy to enhance the penetration of peptides across the BBB. It has been reported that certain peptide drugs, such as DADLE (Tyr-D-Ala-GlyPhe-D-Leu) and thyrotropin-releasing hormone has been delivered to brain using molecular packaging.

\section{Biological Approaches}

For biological approaches a thorough consideration of physiology and anatomy of brain and its barrier regarding its transportation is necessary.

\section{Receptor/Vector-Mediated Delivery of Chimeric Peptides}

Peptide and protein therapeutics have negligible permeability to the brain capillary endothelium. So, these are normally left out from transport from blood to brain. For these peptide drugs the chimeric peptide strategy can be used to deliver across the brain. When a nontransportable peptide therapeutic is coupled to a BBB drug transport vector, a chimeric peptide is formed. Transport vectors are proteins such as cation albumin or the OX26 monoclonal antibody to the transferrin receptor; these proteins undergo absorptive-mediated and receptor-mediated transcytosis through the BBB, respectively. ${ }^{39}$

\section{Cell-Penetrating Peptide (CPP)-Mediated Drug Delivery}

CPPs consist of various amino acids sequence of different size giving a positive charge on the peptide. These can transport the molecules that are tagged to them across the cell membrane and even across BBB. The first CPP, Trans-Activator of Transcription (TAT), derived from Human Immunodeficiency Virus-1 (HIV1), can be efficiently taken up from the surrounding media, regarded to be the first group of CPPs derived from natural proteins. The second group of CPPs con- sists of chimeric molecules, such as Transportan (TP), which consists of 12 amino acids derived from the neuropeptide galanin fused with a 14 amino acid peptide from the wasp venom mastoparan. The third group of CPPs consists of the synthetic peptide family, of which polyarginines are the best studied. ${ }^{40}$

\section{Viral Vectors}

The delivery of recombinant genes into the brain is becoming an increasingly important approach for responding queries related to the molecular mechanisms of brain function. HSV possesses several features that make it an ideal vector for delivery of genes into the nervous system. ${ }^{41}$

\section{Colloidal Drug Carriers}

Micelles and microemulsions Theoretically, natural polymer and synthetic polymer materials can be used to prepare micelles and microemulsions. Currently, polymeric micelles, which are the most investigated, usually have a hydrophobic polymer core (eg, poly (propylene glycol), poly (D, L-lactide) and poly (caprolactone)) and a shell of hydrophilic polymer blocks (eg, poly (ethylene glycol) [PEG]).

\section{Liposomes}

Liposome-based strategies for effective drug delivery across the blood-brain barrier have been used for their unique physico-chemical characteristics. Liposome are used in drug delivery and in vivo bioimaging for the treatment and/or diagnosis of neurological diseases, such as Alzheimer's, Parkinson's, stroke and glioma. For receptor-targeting liposomes, they are covalently attached with macromolecules like peptides, antibodies and RNA aptamers which allows their blood-brain barrier penetration and/or the delivery of their therapeutic molecule specifically to the disease site effective. ${ }^{42}$

\section{NPs (Nanospheres and Nanocapsules)}

Nanoparticles with certain surface modifications can deliver drugs of interest beyond the BBB for diagnostic and therapeutic applications in neurological disorders. In addition to this, it also prevents opsonization. The different physico-chemical properties of the NPs due to different surfactant concentrations, stabilizers and amyloid-affinity agents could influence the transport mechanism. ${ }^{43}$

\section{Alternative Routes}

Use of alternative routes to overcome the physiological barriers like $\mathrm{BBB}$ and $\mathrm{BCFB}$ are intranasal drug delivery and trigeminal pathways. The nose-brain pathway helps rapid transport of lipophilic and small drug molecules 
to CNS within few minutes. Many researchers has carried out delivery of drug via this route, research reports of Sharareh et al. had proved that when NLCs of valporic acid were formulated and administered through intranasal route in rats they showed that brain: plasma concentration ratio was much higher and provided a better protection against MES seizure. ${ }^{44}$

Abdelrahmana et al. had formulated cubosomal gel of risperidone and administered through intranasal route to enhance permeability and biodistribution to brain. They prepared these cubosomal gel using glycerol mono-oleate, Pluronic F127 and Tween 80 and evaluated their particle size polydispersity index, zeta potential, entrapment efficiency, in vitro drug release and transmission electron microscopy. They found that these Cubosome showed drastically elevation in intranasal permeation and better distribution to the brain, when compared to the used control (Drug solution and/or suspension). ${ }^{45,46}$

\section{Invasive Method}

Very few orally or parenterally administered drugs and peptides can cross BBB but cause systemic toxicity before reaching target areas in the brain. To overcome this, invasive methods are used to deliver sufficient amount of therapeutic agents directly to the brain by disrupting the BBB. ${ }^{47}$

\section{Intraventricular Delivery/Intrathecal Delivery}

The intraspinal routes of the drug administration is comprised of intrathecal and epidural drug delivery where the drug is administered to the cerebrospinal fluid. In case of intrathecal delivery the drug is directly injected into the CSF present in the intrathecal space in the spinal column, but in case of drugs which are injected in the epidural space have to cross the dura membrane to get to the CSF so there are chances that drug administered through epidural space can also reach the systemic circulation so the intrathecal route reduces the side effects of drugs compared to that of systemic routes of drug delivery. The intrathecal route administer the drug directly into the CSF circumventing the blood brain barrier. Persistent intracranial drug concentration of anticancer drug was achieved by administering locally to an intracarnial target. ${ }^{48-50}$

\section{BBB Disruption (BBBD) strategies}

It was reported by, Rapoport et al. that CNS tissues were stained by Evans Blue as a result of intra-arterial infusion of hypertonic arabinose. ${ }^{51}$ Evans Blue which binds to albumin do not permeate through intact $\mathrm{BBB}$; the above observation suggests that permeability of $\mathrm{BBB}$ is changed by hypertonic arabinose which induces contraction of cerebrovascular endothelial cells causing distraction of inter-endothelial tight junctions. This hypothesis was supported by Brightman and co-workers when they effectively visualized opened endothelial tight junctions with electron microscopy after intra-carotid infusion of mannitol in several species. ${ }^{52}$ In 1984, Dorovini-zis et al. also practically observed opened inter-endothelial tight junctions when endothelial cell cultures were exposed to a hypertonic solution. ${ }^{53}$

\section{Intracerebral Implants}

In most of the clinical trials intracerebral implantation are utilized which contains therapeutic agents imbibed in biodegradable polymeric matrix or reservoir. The FDA approved a BCNU (bischloroethylnitrosourea) (carmustine)-contained polyanhydride polymer wafer for recurrent high-grade gliomas in $1996 .{ }^{54}$ This matrix was made with a blend of diffusion and hydrolytic polymers and maintains a sustained drug release for about 2 months. Intracerebral implantation has also been tried in some chemotherapeutics. ${ }^{55-57}$ But the augmented risk of trauma and poor drug infiltration beyond the resection cavity restricted the local delivery approach.

\section{Convection-Enhanced Delivery (CED)}

The therapeutic agents are administered directly into the embattled brain parenchyma or tissue by CED. One and more catheter stereo tactically placed through cranium by inflecting holes into the brain in CED. The micro infusion pump are used to administer the therapeutic agents. ${ }^{58,59}$ CED has shown its exceptional characteristics for CNS delivery compared with conventional delivery methods. ${ }^{60}$ When defined infusion measurements are used through CED it does not produce cerebral edema or measurable increase in intracranial pressure. ${ }^{61}$ Bobo et al. first proposed CED in 1994. ${ }^{2}$ CED involves maintenance of continuous positive-pressure infusion of a solute containing a therapeutic agent. It relies on pressure-driven bulk flow of infuscate for delivering therapeutic agents to the CNS. The bulk flow mechanism is created by a small pressure gradient from a pump that pushes solute through a catheter targeted within the CNS.: (i) CED bypasses the BBB and can be used to infuse therapeutic agents with large or small molecular weights via bulk interstitial flow; (ii) CED provides targeted delivery to the region into which the catheter is placed and the potential for real-time monitoring of distribution, which would allow intelligent adjustment of flow rates; (iii) and unlike diffusion-limited delivery, CED provides pressure-driven delivery that enhances interstitial drug distribution. ${ }^{63}$

\section{Biological Tissue Delivery}

This is one of the approaches to accomplish interstitial drug delivery from biological tissue. In this method, a tissue is implanted into the brain that secrets a desired 
therapeutic agent. This strategy was used to treat Parkinson's disease. ${ }^{64}$ But due to lack of neovascular innervations the transplanted tissue dies soon. With advancement in the technique the survival of foreign tissue grafts is improved. In recent times it has been established that superior vascularization and microvascular permeability occurs in cell-suspension embryonic neural grafts as compared to solid grafts. ${ }^{65,66}$

\section{Recent Development in Lipid Nanoparticles to Combat Infectious Brain Diseases}

Nanoparticles used in CNS disorders: In infectious condition the $\mathrm{BBB}$ get disrupted but the main problem associated with it is the rejuvenation of $\mathrm{BBB}$ as the infection starts to cure and after which the required amount of drug is not available to the site. It has been found by many researchers that nanoparticles especially surfactant coated and lipid nanoparticles has mammoth contribution in escalating biodistribution of drugs in $\mathrm{CNS}$ as well as increases the retention in BBB. Based on the above considerations, a proper tuning of NP surface characteristics and size, can represent a highly important approach to alter NP biodistribution, thus, enhancing their blood circulation time and deposition in non-RES organs ${ }^{67,68}$ In this article we briefly discuss on the various work done in this field.

\section{Outline of Various Mechanisms for Nanoparticle Mediated Drug Uptake by the Brain}

1. Enhanced retention in the brain-blood capillaries, with an adsorption on to the capillary walls, resulting in a high concentration gradient across the BBB.

2. Opening of tight junctions due to the presence of nanoparticles.

3. Transcytosis of nanoparticles through the endothelium.

Nano carriers increases pharmacokinetics and biodistribution while minimizing the toxicity of therapeutic agents at the site of accumulation because these nanocarriers have larger ratio of surface area and volume. ${ }^{69,70}$ Nanoparticles used to deliver drugs against CNS infection.

Nano particles for the treatment of Human African Trypanosomiasis (HAT) were designed. The causative agent of HAT T. brucei resides, mainly, in the blood stream. Flaig et al. have studied the worth of daunomycin nanoparticles against the blood forms of T. brucei. ${ }^{71-73}$ Both Growth inhibition and trypanocidal action of nanoparticulate daunomycin either plain or coated with PEG, transferrin, human serum albumin and transferrin antibodies was evaluated. On the T. brucei surface transferrin receptors are expressed, the highest effec- tiveness was observed with transferring receptor antibody and transferrin coupled nanoparticles signifying the usefulness of surface receptors targeting approach. From the biodistribution studies of these nanoparticles it was conclusive that they are also transported to the brain, which could be very useful in the chronic phase of trypanosomiasis.

\section{Lipid Nanoemulsion}

Lipid nanoemulsion are prepared by the dispersion of two immisible liquid in which one is water and the other is oily phase. The mean particle size is less than $500 \mathrm{~nm}$ and these ultrafine dosages form plays a very important role in enhancing the bioavailibility of poorly water soluble drugs and also increases the permeability and retention of polar drug. ${ }^{74}$ Due to small particle size they have more kinetic stability compared to the coarse emulsion. Nanoemulsion protect the drug against severe physiological conditions (like $\mathrm{pH}$, oxidation and hydrolysis) and also used to solubilize in parenteral form. ${ }^{75}$ Hitendra et al. formulated intranasal nanoemulsion of saquinavir mesylate targeting CNS (anti-HIV drug with poor solubility and permeability) and found that the permeability of drug through BBB was significantly increased. ${ }^{76}$

\section{Liposomes}

Liposomes are bilayer vesicular structure made up of phospholipids and cholesterol surrounding the aqueous compartment, which may be multilamellar or unilamellar. Liposomes due to their inimitable physico-chemical characteristics are able to include both hydrophilic and lipophilic. Lipophilic drugs are entrapped in the lipid bilayer while hydrophilic drugs are entrapped in the aqueous compartment. Liposomes are biocompatible, biodegradable, less toxicity, target specific and can control drug release. The surface of liposomes can be modified by addition of macromolecules like polymers, polysaccharides, peptides, antibodies or aptamers to improve blood circulation and brain-specific delivery. ${ }^{77-80}$

Liposome-based drugs developed for brain-targeted drug delivery are now in various stages of development. Researchers ${ }^{81,82}$ have developed liposome-based amphotericin B for treatment of cryptococcal meningitis. Similarly, cytarbine ${ }^{83}$ is being developed for treatment of lymphomatous meningitis. Lippens ${ }^{84}$ has used DSPC and cholesterol for developing liposomal daunorubicin, which is in phase I of clinical trial, for treatment of pediatric brain tumor. Liposome based doxorubicin ${ }^{85-91}$ is in phase II of clinical trial. There is a patent to conjugates and liposomes are used for targeted drug delivery 
of drugs to intracellular target sites within cells, tissues and organs, in particular to target sites within the central nervous system (CNS), into and across the blood-brain barrier, by targeting to internalizing uptake receptors present on these cells, tissues and organs. ${ }^{92}$

\section{Lipid Nanoparticles}

Lipid nanoparticles are made of solid lipophilic matrix embedded with drug molecules with their size ranging between 150 to $300 \mathrm{~nm}$ but depending on requirement the size can be varied from less than 100 to $1000 \mathrm{~nm}$. These lipid nanoparticles are prepared by replacing the liquid lipid used in emulsions with the solid lipids. The solid lipids used are of high-melting point glycerides or waxes to produce SLN. The advantage of lipid nanoparticles is that it remains solid even after administration to the body so they provide controlled release. There are two generations of lipid nanoparticles, first generation are solid lipid nanoparticle, which are made of solid lipids only and the second generation are nanostructure lipid carriers, in which both solid lipid and liquid lipids are used. Due to the inclusion of the oil compound the perfect lipid structure get destroyed and this, in turn, forms a imperfect structure or amorphous form which increases the loading volume for drug. So, if we compare SLN and NLC the latter has imperfect structure hence the loading capacity increases and there is a less chance of drug expulsion over time or during sterilization than the former. One more problem associated with solid lipids, as for SLN, is that they undergo polymorphic changes which leads to drug expulsion and causes precipitation of drug in aqueous phase. But these problems can be resolved by addition of liquid lipids to the solid lipids. ${ }^{93,44}$ Hence NLC possess a higher physical stability than SLN.

Lipid nanoparticles (NLC, SLN) are composed of hydrophobic biodegradable carrier lipids and the drug is either dissolved or dispersed in the core, thus, rending it suitable for administrating through $\mathrm{IV} .^{95}$ The small size of lipid nanoparticle causes it to cross tight endothelial cells of BBB in CNS and bypass reticuloendothelial system and liver. In addition, these lipid nanoparticles provide higher drug entrapment efficiency, more stability to drug in lipid matrix and prolonged release of drug for longer period of time, which, at times, may last for several weeks. Sometimes the surface of these lipid nanostructure are coated with hydrophilic (Cationic) polymer or surfactant so that they can penetrate the BBB. ${ }^{96}$

Most of the antimicrobial's agents targeting CNS infection has problem in crossing the barriers present in the brain. So, lipid nanoparticles are used as carriers and administered parenterally or through nasal route.
Lipid nanoparticles possesses advantage of controlled release over nanoemulsion, when drug loaded nanoemulsions are injected the drug partitions from the oil phase to aqueous phase of blood in few seconds, depending on the $\log$ P of the drug. Thus, lipid nanoparticles remain in circulation for a longer time.

Bondi et al. have patented a NLC based riluzole for treatment of sclerosis. The authors used compitrol as solid lipid for the preparation of NLC and have effectively demonstrated that NLC based riluzole crossed BBB more easily than free riluzole. ${ }^{97}$ Awasthi and Lagisetty have developed and patented a variety of solid lipids (2carboxyheptadecanoyl heptadecylamide (CHHDA), 1,4dipalmitoyl-tartarate-2,3-disuccinic acid (DPTSA), 1,4-di palmitoyl-tartarate-2,3-diglutaric acid (DPTGA) or Cholesteryl Hemisuccinate (CHEMS)) and used these solid lipids along with Vitamin E as liquid lipid for preparing lipid matrix. ${ }^{98}$ Wang et al. have successfully bound a biotinylated protein antibody to lipid nanoparticles that can recognize a receptor on surface of a neuronal cell and, hence can target cells of CNS or PNS. ${ }^{99}$ Gupta et al. had investigated the delivering ability of Transferrin (Tf) conjugated solid lipid nanoparticles loaded with quinine dihydrochloride to brain for the management of cerebral malaria. SLNs were prepared by an ethanol injection method using hydrogenated soya phosphatidyl choline (HSPC), Triolein, cholesterol and distearyl phosphatidylethanolamine (DSPE). Coupling of SLNs with $\mathrm{Tf}$ was achieved by incubation of $\mathrm{Tf}$ with quinine-loaded SLNs in the presence of 1-ethyl3-(3-dimethylaminopropyl) carbodiimide (EDC) hydrochloride in phosphate buffered saline $(\mathrm{pH} 7.4)$ as a cross-linker. The particle size range of SLNs formed and drug entrapment was 38.4-42.7\%. A dialysis technique was used to determined the in-vitro release profile. The release rate of non-conjugated SLNs was more than Tf-SLNs but the fluorescence studies revealed that the uptake of Tf-SLNs in brain tissue is more compared to that of unconjugated SLNs. They also found that in case of intravenous administration of quinine dihydrochloride solution the concentration of drug in the serum was much higher concentrations than with SLNs. ${ }^{100}$ Manoj Kumar et al. had prepared SLN of streptomycin by nano colloidal aqueous dispersion technique to increase the permeability of streptomycin sulphate through $\mathrm{BBB}$ to $\mathrm{CNS}$ via nasal route. The authors found that the biodistribution of streptomycin sulfate increases 3.15 and 11.0 times more in brain and blood respectively compared to free streptomycin sulphate administered through IN route. ${ }^{101}$

Inability to cross the blood-brain barrier and deliver drugs to the central nervous system has hindered the 
developments of nanocarriers. ${ }^{102}$ On the other hand, the highly vascularized nature of brain tissue makes it an attractive choice for intravenous delivery of therapeutic drugs. SLN and NLC take benefit of the high capillary density of the brain and at the same time has the capability to overcome blood-brain barrier restrictions. ${ }^{100}$ Using these formulations the delivery of antiretrovirals to the brain, such as the HIV protease inhibitor Atazanavir have been boosted. ${ }^{103}$ Researchers have also demonstrated that thiamine-coated SLN successfully bind to the blood brain barrier thiamine transporter and result in a gradual buildup of SLN that is responsible for increased brain uptake. ${ }^{104}$ SLN and NLC shows potential drug-delivery systems, but in the case of the brain, they are even more important in terms of successfully overcoming the limitation imposed by the blood-brain barrier. ${ }^{105} \mathrm{Lipid}$ nanocarriers are well known to cross the BBB and exhibit required therapeutic effect without surface modification of drugs. SLNs and NLCs were found to bind Apolipoproteins and target brain tissues like polymeric nanoparticles containing PBCA. ${ }^{106}$ Lim et al. had developed and characterized itraconazole (ITZ)-loaded nanostructured lipid carriers (NLCs) using Precirol ${ }^{\circledR}$ ATO 5 and Transcutol ${ }^{\circledR}$ HP as the lipid phase and Tween ${ }^{\circledR} 80$ and Solutol ${ }^{\circledR}$ HS15 as surfactants. The ITZ-NLCs were prepared by a hot and high-pressure homogenization method. The entrapment efficiency for the best formulation batch was analyzed using highperformance liquid chromatography and was found to be $70.5 \% \pm 0.6 \%$. The average size, zeta potential and polydispersity index for the ITZ-NLCs used for animal studies were found to be $313.7 \pm 15.3 \mathrm{~nm},-18.7 \pm 0.30$ $\mathrm{mV}$ and $0.562 \pm 0.070$, respectively. Transmission electron microscopy confirmed that ITZ-NLCs were spherical in shape, with a size of less than $200 \mathrm{~nm}$. An in vivo study showed that ITZ-NLCs could increase the ITZ concentration in the brain by almost two-fold. ${ }^{107}$

\section{CONCLUSION}

The astonishing growth in current years of CNS drugs has generated massive research scope in the develop of new dosage forms for brain diseases. The main challenges involved in targeting brain are the blood brain barrier and efflux transport mechanism. Various strategies were attempted in order to overcome this issue, but the best answer obtained were by using lipid nanoparticles e.g. SLN, NLC, LDC NPs, these forms indicate less toxicity, production feasibility and scalability compared to other formulations. The main problem associated with these forms are selection of lipids and surfactants. But it has been found by researchers the toxicity of surfactants becomes less in these lipid formulations. ${ }^{108}$ Moreover, the high vascularization of brain facilitates the transfer of these dosages form through intravenous parenteral. When we discuss about the infectious diseases it is required that the drug should reach to the CNS and remain there till the infection is completely cured. However, the main problem associated with antibiotics is that the microbial resistance variants is a serious threat fighting against infectious diseases.

\section{ACKNOWLEDGEMENT}

The Authors would like to sincerely thank NIET, Pharmacy Institute for providing infrastructure for carrying out this study.

\section{CONFLICT OF INTEREST}

The authors declare no conflict of interest.

\section{ABBREVIATIONS}

CNS: Central nervous system; PNS: Peripheral nervous system; CP: Choroid plexus; BCFB: Blood cerebrospinal fluid barrier; CSF: Cerebrospinal fluid; ISF: Interstitial fluid; BBB: Blood brain barrier; ABC: ATPbinding cassette; ATP: Adenosine triphosphate; P-gp: Permeability glycoprotein; BCRP: Breast cancer resistance protein; MRP: Mitochondrial RNA processing; DADLE: [D-Ala2,D-Leu5]-Enkephalin; CPP: Cell penetration peptide; TAT: Trans-activator of transcription; TP: Transportan; HSV: Herpes simplex virus; HIV: Human immuno deficiency virus; PEG: Polyethylene glycol; NLCs: Nanostructured lipid carriers; MES: Maximum electroshock seizure; BCNU: Bischloro ethyl nitroso urea; FDA: Food and drug authority; CED: Convention-enhanced delivery; RES: Reticuloendothelial system; HAT: Human African Trypanosomia; HSPC: Hydrogenated soya phosphatidyl choline; DSPE: Distearyl phosphatidyl ethanolamine; CHHDA: 2carboxyheptadecanoyl heptadecylamide; DPTSA: 1,4dipalmitoyl-tartarate-2,3-disuccinic acid; DPTGA: 1,4-di palmitoyl-tartarate-2,3-diglutaric acid; CHEMS: Cholesteryl hemisuccinate; Tf: Tissue factor; EDC: 1-ethyl-3-(3-dimethylaminopropyl)carbodiimide hydrochloride; PBCA: Polybutylcyanoacrylate; ITZNLCs: Itraconazole-loaded nanostructured lipid carriers; LDC NPs: Lipid drug conjugated nanoparticles.

\section{REFERENCES}

1. Neuwelt E, Abbott NJ, Abrey L, Banks WA, Blakley B, Davis T, et al. Strategies to advance translational research into brain barriers. Lancet Neurol. 2008;7(1):84-96. 
2. Cohen ML. Changing patterns of infectious disease. Nature. 2000;406(6797):762-7.

3. Gold HS, Moellering RC. Antimicrobial-drug resistance. N Engl J Med. 1996;335(19):1445-53.

4. Walsh C. Molecular mechanisms that confer antibacterial drug resistance. Nature. 2000;406(6797):775-81.

5. Prusiner SB. Molecular Biology of Prion Diseases. Science. 1991;252(5012):1515-22.

6. Shakir R. Infectious diseases of the nervous system. Brain. 2001;124(10):2121.

7. Medicalnewstoday.com. GDPR consent required. [online] Available at: https://www.medicalnewstoday.com/articles/321031.php.

8. Brouwer M, Coutinho J, DeBeek DV. Clinical characteristics and outcome of brain abscess: Systematic review and meta-analysis. Neurology. 2014:82(9):806-13.

9. Robert-Gangneux F, Darde M. Epidemiology of and Diagnostic Strategies for Toxoplasmosis. Clinical Microbiology Reviews. 2012;25(2):264-96.

10. Beare NA, Lewallen S, Taylor TE, Molyneux ME. Redefining cerebral malaria by including malaria retinopathy. Future Microbiol. 2011:6(3):349-55.

11. Cetin N, Blackall D. Naegleria fowleri meningoencephalitis. Blood. 2012;119(16):3658.

12. Rockwood R. Extrapulmonary TB. The Nurse Practitioner. 2007;32(8):44-9.

13. Science Daily. New Leprosy Bacterium: Scientists Use Genetic Fingerprint to Nail 'Killing Organism'. 2018. [online] Available at: https://www.sciencedaily. com/releases/2008/11/081124141047.htm

14. Mehrabian S, Raycheva M, Traykova M, Stankova T, Penev L, Grigorova O, et al. Neurosyphilis with dementia and bilateral hippocampal atrophy on brain magnetic resonance imaging. BMC Neurology. 2012;12(1):96.

15. Fowler M, Yin K, Humphries H, Heckels J, Christodoulides M. Comparison of the Inflammatory Responses of Human Meningeal Cells following Challenge with Neisseria lactamica and with Neisseria meningitidis. Infection and Immunity. 2006;74(11):6467-78.

16. Shapiro E. Lyme Disease. New England Journal of Medicine. 2014;370(18):1724-31

17. Koedel U, Fingerle V, Pfister $H$. Lyme neuroborreliosis-epidemiology, diagnosis and management. Nature Reviews Neurology. 2015;11(8):446-56.

18. Logan S, Mahon EM. Viral meningitis. BMJ. 2008;336(7634):36-40.

19. Thompson RA, Green JR. Infectious Diseases of the Central Nervous System in: Advances in Neurology. New York Raven Press. 1974;16.

20. Johanson CE. Ventricles and cerebrospinal fluid. In: Neuroscience in Medicine. Lippincott, Philadelphia. 1995;171-96.

21. Brightman MW, Reese TS. Junctions between intimately apposed cell membranes in the vertebrate brain. Journal of Cell Biology. 1969;40(3):64877.

22. Mason JC, Curry FE, White IF, Michel CC. The ultrastructure of frog mesenteric capillaries of known filtration coefficient. Quarterly Journal of Experimental Physiology. 1979;64(3):217-24.

23. Pardridge WM. The blood-brain barrier: bottleneck in brain drug development. Neuro Rx. 2005;2(1):3-14.

24. Begley DJ. The blood-brain barrier: principles for targeting peptides and drugs to the central nervous system. J Pharm Pharmacol. 1996;48(2):13646.

25. Crone C. The blood-brain barrier: a modified tight epithelium. Ellis Harwood Chichester. 1986;17-40.

26. Brightman M. Ultrastructure of brain endothelium. In Physiology and pharmacology of the blood-brain barrier. Handbook of experimental pharmacology 103, Springer-Verlag, Berlin. 1992;1-22.

27. Santaguida S, Janigro D, Hossain M, Oby E, Rapp E, Cucullo L, et al. Side by side comparison between dynamic versus static models of blood-brain barrier in vitro: a permeability Study. Brain Research. 2006;1109 (1):1-13.

28. Huttunen KM, Rautio J. Prodrugs-an efficient way to breach delivery and targeting barriers. Current Topics in Medicinal Chemistry. 2011;11(18):226587.

29. Davson H, Segal MB. Physiology of the CSF and Blood-Brain Barriers. CRC Press New York. 1995.

30. Strazielle N, Ghersi-Egea JF. Choroid plexus in the central nervous system: Biology and physiopathology. J Neuropathol Exp Neurol. 2000;59(7):561-74.
31. Zheng W, Aschner M, Ghersi-Egea JF. Brain barrier systems: A new frontier in metal neurotoxicological research. Toxicol Appl Pharmaco. 2003;192(1):111.

32. Saier MH, Paulsen IT. Phylogeny of multidrug transporters. Seminars in Cellular and Developmental Biology. 2001;12(3):205-13.

33. Poolea K. Efflux pumps as antimicrobial resistance mechanisms pages. Annals of Medicine. 2007;39(3):162-76.

34. Jain A, Jain K. Drug Targeting to the Brain - A Review. Current Nanoscience. 2011;7(1):21-36.

35. Jong WHD, Borm PJA. Drug delivery and nanoparticles: Applications and hazards. International Journal Nanomedicine. 2008;3(2):133-49.

36. Seelig A, Gottschlich R, Devant RM. A method to determine the ability of drugs to diffuse through the blood-brain barrier. Proceedings of the National Academy of Sciences of the United States of America. 1994;91(1):68-72.

37. Levy S, Marshall B. Antibacterial resistance worldwide: causes challenges and responses. Nature Medicine. 2004;10(12s):S122-9.

38. Masserini M. Nanoparticles for Brain Drug Delivery. ISRN Biochemistry. 2013;1-18.

39. Bickel U, Yoshikawa T, Pardridge W. Delivery of peptides and proteins through the blood-brain barrier. Advanced Drug Delivery Reviews. 2001;46(1-3):24779.

40. Zou L, Ma J, Wang T, Yang T, Liu C. Cell-Penetrating Peptide-Mediated Therapeutic Molecule Delivery into the Central Nervous System. Current Neuropharmacology. 2013;11(2):197-208.

41. Fink D, DeLuca N, Goins W, Glorioso J. Gene Transfer to Neurons Using Herpes Simplex Virus-Based Vectors. Annual Review of Neuroscience. 1996;19(1):265-87.

42. Vieira D, Gamarra L. Getting into the brain: liposome-based strategies for effective drug delivery across the blood brain barrier. Int $\mathrm{J}$ Nanomedicine. 2016;11:5381-414.

43. Roney C, Kulkarni P, Arora V, Antich P, Bonte F, Wu A, et al. Targeted Nanoparticles for Drug Delivery through the Blood Brain Barrier for Alzheimer's Disease. Journal of Controlled Release. 2005;108(2-3):193-214.

44. Eskandari S, Varshosaz J, Minaiyan M, Tabbakhian M. Brain delivery of valproic acid via intranasal administration of nanostructured lipid carriers: in vivo pharmacodynamic studies using rat electroshock model. Int J Nanomedicine. 2011;6:363-71.

45. Lu C, Zhao Y, Wong H, Cai J, Peng L, Tian X, et al. Current approaches to enhance CNS delivery of drugs across the brain barriers. Int J Nanomedicine. 2014;9:2241.

46. Jogani V, Jinturkar K, Vyas $\mathrm{T}$, et al. Recent patents review on intranasal administration for CNS drug delivery. Recent Pat Drug Deliv Formul. 2008;2(1):25-40.

47. Wang PP, Frazier J, Brem H. Local drug delivery to the brain. Adv Drug Deliv Rev. 2002;54(7):987-1013

48. Pharmaceutical Journal. Intrathecal route of drug delivery can save lives or improve quality of life. 2018. [online] Available at: https://www.pharmaceuticaljournal.com/research/perspective-article/intrathecal-route-of-drug-deliverycan-save-lives-or-improve-quality-of-life/11110496.fullarticle.

49. Greig NH. Optimizing drug delivery to brain tumors. Cancer Treat Rev. 1987;14(1):1-28.

50. Harbaugh RE, Saunders RL, Reeder RF. Use of implantable pumps for central nervous system drug infusions to treat neurological disease. Neurosurgery.1988;23(6):693-8.

51. Blanchette M, Fortin D. Blood-brain barrier disruption in the treatment of brain tumors. US National Library of Medicine National Institutes of Health Methods Mol Biol. 2011;686:447-63.

52. Brightman MW, Hori M, Rapoport I, Reese TS, Wester GE. Osmotic opening of tight junctions in cerebral endothelium. J Comp Neurol. 1973;152(4):31725.

53. Dorovini-Zis K, Bowman PD, Betz AL, Goldstein GW. Hyperosmotic arabinose solutions open the tight junctions between brain capillary endothelial cells in tissue culture. Brain Res. 1984;302(2):383-6.

54. Westphal M, Hilt DC, Bortey E, Delavautt P, Olivares R, Warnkle PC, et al. A phase 3 trial of local chemotherapy with biodegradable carmustine (BCNU) wafers (Gliadel wafers) in patients with primary malignant glioma. Neuro Onco. 2003;5(2):79-88. 
55. Vukelja SJ, Anthony SP, Arseneau JC, Berman BS, Cunningham CC, Nemunaitis JJ, et al. Phase 1 study of escalating dose OncoGel (ReGel/ paclitaxel) depot injection, a controlled-release formulation of paclitaxel, for local management of superficial solid tumor lesions. Anticancer Drugs. 2007;18(3):283-9.

56. Sheleg SV, Korotkevich EA, Zhavrid EA, Muravskaya GS, Smeyanovich AF, Shankho YG, et al. Local chemotherapy with cisplatin-depot for glioblastoma multiforme. J Neurooncol. 2002;60(1):53-9.

57. DiMeco F, Li KW, Tyler BM. Local delivery of mitoxantrone for the treatment of malignant brain tumors in rats. J Neurosurg. 2002;97(5):1173-8.

58. Cunningham J, Pivirotto P, Bringas J. Biodistribution of adeno-associated virus type-2 in nonhuman primates after convection-enhanced delivery to brain. Mol Ther. 2008;16(7):1267-75.

59. Bidros DS, Vogelbaum MA. Novel drug delivery strategies in neuro-oncology. Neurotherapeutics. 2009;6(3):539-46.

60. Winn RH, Bidros D, Vogelbaum MA. Barriers to delivery of therapeutics to brain tumors. In: WinnRH, editor. Youman's Neurological Surgery. $6^{\text {th }}$ ed. Philadelphia: Elsevier Saunders. 2011;1172-8.

61. Chen MY, Lonser RR, Morrison PF, et al. Variables affecting convectionenhanced delivery to the striatum: a systematic examination of rate of infusion, cannula size, infusate concentration and tissue cannula sealing time. J Neurosurg. 1999;90(2):315-20.

62. Bobo RH, Laske DW, Akbasak A, et al. Convection-enhanced delivery of macromolecules in the brain. Proc Natl Acad Sci USA. 1994;9(6):2076-80.

63. Varenika $\mathrm{V}$, Dickinson $\mathrm{P}$, Bringas $\mathrm{J}$, et al. Detection of infusate leakage in the brain using real-time imaging of convection-enhanced delivery. J Neurosurg. 2008;109(5):874-80.

64. Sladek JR, JrGash DM. Nerve-cell grafting in Parkinson's disease. J Neurosurg. 1988;68(3):337-51.

65. Leigh K, Elisevich K, Rogers KA. Vascularization and microvascular permeability in solid versus cell-suspension embryonic neural grafts. $J$ Neurosurg. 1994;81(2):272-83.

66. Cui-Tao L, Ying-Zheng Z, Ho LW, Jun C, Lei P, Xin-Qiao T. Current approaches to enhance CNS delivery of drugs across the brain barriers. Int $\mathrm{J}$ Nanomedicine. 2014;9:2241-57.

67. Stamatovic SM, Keep RF, Andjelkovic AV. Brain Endothelial Cell-Cell Junctions: How to "Open" the Blood Brain Barrier. Curr Neuropharmacol. 2008;6(3):179-92.

68. Salunkhe SS, Bhatia NM, Kawde VS, Bhatia MS. Development of Lipid Based Nanoparticulate Drug Delivery Systems and Drug Carrier Complexes for Delivery to Brain. J App Pharm Sci. 2015;5(5):110-29.

69. Alexis F, Rhee JW, Richie JP, Rodavic-Moreno AF, Robert LR, Farokhzad $\mathrm{OC}$, et al. New frontiers in nanotechnology for cancer treatment. Urol Oncol. 2008;26(1):74-85.

70. Mishra B, Patel BB, Tiwari S. Colloidal nanocarriers: a review on formulation technology, type and applications toward targeted drug delivery. Nanomedicine: Nanotechnology, Biology and Medicine. 2010;(6):9-24.

71. Langevin D. Microemulsions LNPs trageting brain are very beneficial for the treatment of CNS diseases like parasitic infections, AIDS, brain tumour, neurological and psychiatric disorder. Acc Chem Res. 1988;21(7):255-60.

72. Kreuter J. Nanoparticulate systems for brain delivery of drugs. Adv Drug Deliv Rev. 2001;47(1):65-81.

73. Flaig R, Rosenkranz V, Wink M, Fricker G. Ktenate nanoparticles (bdellosomes): a novel strategy for delivering drugs to parasites or tumors. $J$ Drug Deliv Sci Technol. 2005;15(1):59-63.

74. Singha $\mathrm{Y}$, Meher JK, Ravala K, Khan FA, Chaurasia M, Jain NK, et al. Nanoemulsion: Concepts, development and applications in drug delivery. Journal of Controlled Release. 2017;252:28-49.

75. Jiang SP, He SN, Li YL, Feng DL, Lu XY, Du YZ, et al. Preparation and characteristics of lipid nanoemulsion formulations loaded with doxorubicin. Int J Nanomedicine 2013,8:3141-50.

76. Mahajan HS, Mahajan MS, Nerkar PP, Agrawal A. Nanoemulsion-based intranasal drug delivery system of saquinavir mesylate for brain targeting. Drug delivery. 2013;148-54.

77. Micheli MR, Bova R, Magini A, Polidoro M, Emiliani C. Lipid-based nanocarriers for CNS-targeted drug delivery. Recent Pat CNS Drug Discov. 2012;7(1):71-86.
78. Schnyder A, Huwyler J. Drug transport to brain with targeted liposomes. Neuro Rx. 2005;2(1):99-107.

79. Johnsen KB, Moos T. Revisiting nanoparticle technology for blood-brain barrier transport: unfolding at the endothelial gate improves the fate of transferrin receptor-targeted liposomes. J Control Release. 2016;222:32-46.

80. Noble GT, Stefanick JF, Ashley JD, Kiziltepe T, Bilgicer B. Ligand-targeted liposome design: challenges and fundamental considerations. Trends Biotechnol. 2014;32(1):32-45.

81. Loyse A, Thangaraj $\mathrm{H}$, Easterbrook P, et al. Cryptococcal meningitis: improving access to essential antifungal medicines in resource-poor countries. Lancet Infect Dis. 2013;13(7):629-37.

82. Robinson RF, Nahata MC. A comparative review of conventional and lipid formulations of amphotericin. BJ Clin Pharm Ther. 1999;24(4):249-57.

83. Benesch M, Urban C. Liposomal cytarabine for leukemic and lymphomatous meningitis: recent developments. Expert Opin Pharmacother. 2008;9(2):3019.

84. Lippens RJ. Liposomal daunorubicin (DaunoXome) in children with recurrent or progressive brain tumors. Pediatr Hematol. 1999;16(2):131-9.

85. Ananda S, Nowak AK, Cher L, et al. Phase 2 trial of temozolomide and PEGylated liposomal doxorubicin in the treatment of patients with glioblastoma multiforme following concurrent radiotherapy and chemotherapy. J Clin Neurosci. 2011;18(11):1444-8.

86. Beier CP, Schmid C, Gorlia T, et al. RNOP-09: PEGylated liposomal doxorubicine and prolonged temozolomide in addition to radiotherapy in newly diagnosed glioblastoma- a phase II study. BMC Cancer. 2009;9(1):308.

87. Hau P, Fabel K, Baumgart U, et al. PEGylated liposomal doxorubicin-efficacy in patients with recurrent high-grade glioma. Cancer. 2004;100(6):1199-207.

88. Chua SL, Rosenthal MA, Wong SS, et al. Phase 2 study of temozolomide and Caelyx in patients with recurrent glioblastoma multiforme. Neuro Oncol. 2004;6(1):38-43.

89. Wagner S, Peters O, Fels C, et al. PEGylated-liposomal doxorubicin and oral topotecan in eight children with relapsed high-grade malignant brain tumors. J Neurooncol. 2008;86(2):175-81.

90. Marina NM, Cochrane D, Harney E, et al. Dose escalation and pharmacokinetics of PEGylated liposomal doxorubicin (Doxil) in children with solid tumors: a pediatric oncology group study. Clin Cancer Res. 2002;8(2):413-18.

91. DiLegge A, Trivellizzi IN, Moruzzi MC, Pesce A, Scambia G, Lorusso D, et al. Phase 2 trial of nonPEGylated doxorubicin (Myocet) as second-line treatment in advanced or recurrent endometrial cancer. Int $\mathrm{J}$ Gynecol Cancer. 2011;21(2):1446-51.

92. To BBB Holding B.V. Conjugates for targeted drug delivery across the bloodbrain barrier. EP2308514. 2011.

93. Acar S, Müller RH, Keck CM. Role of alpha- modification on physical stability of lipid nanoparticles. Annual Meeting of German Pharmaceutical Society (DPhG), Braunschweig. 2010.

94. Acar S, Keck CM. Menthol loaded NLC: Reproducibillity and influence of production parameters on physicochemical properties. Int $\mathrm{J}$ Pharm in preparation. 2010

95. Marcato PD, Durán N. New aspects of nanoparmaceutical delivery systems. J Nanosci Nanotechnol. 2008;8(5):2216-29.

96. Rainer HM, Ranjita S, Cornelia MK. 20 Years of Lipid Nanoparticles (SLN and NLC): Present State of Development and Industrial Applications. Current Drug Discovery Technologies. 2011;8(3):207-27.

97. Bondi ML, Giammona G, Craparo EF, Drago F. Nanostructured lipid carriers containing riluzole and pharmaceutical formulations containing said particles. US20100247619. 2010.

98. Awasthi V, Lagisetty P. Anionic lipids and lipid nano-structures and methods of producing and using same. US20110059157. 2011.

99. Wang KK, Wang J, Goodman JV, Larner SF. Antibody bound synthetic vesicle containing molecules for deliver to central and peripheral nervous system cells. US20110097392. 2011.

100. Gupta Y, Jain A, Jain SK. Transferrin-conjugated solid lipid nanoparticles for enhanced delivery of quinine dihydrochloride to the brain. Pharm Pharmacol. 2007;59(7):935-40.

101. Kumar M, Kakkar V, Mishra AK, Chuttani K, Kaur IP. Intranasal delivery of streptomycin sulfate (STRS) loaded solid lipid nanoparticles to brain and blood. International Journal of Pharmaceutics. 2014;461(1-2):223-33. 
102. Abhijit A, Date B, Medha D, Joshi A, Vandana B, Patravale A, et al. Parasitic diseases: Liposomes and polymeric nanoparticles versus lipid nanoparticles. Advanced Drug Delivery Reviews. 2000;59(6):505-21.

103. Muthu MS, Singh S. Targeted nanomedicines effective treatment modalities for cancer, AIDS and brain disorders. Nanomedicine. 2009;4(1):105-18.

104. Barbu E, Molnar E, Tsibouklis J, Gorecki DC. The potential for nanoparticlebased drug delivery to the brain overcoming the blood-brain barrier. Expert Opinion on Drug Delivery. 2009;6(6):553-65.

105. Chattopadhyay N, Zastre J, Wong HL, Wu XY, Bendayan R. Solid lipid nanoparticles enhance the delivery of the HIV protease inhibitor, atazanavir, by a human brain endothelial cell line. Pharm Res. 2008;25(10):2262-71.
106. Lockman PR, Oyewumi MO, Koziara JM, Roder KE, Mumper RJ, Allen DD, et al. Brain uptake of thiamine-coated nanoparticles. J Control Release. 2003;93(3):271-82.

107. Lim WM, Rajinikanth PS, Mallikarjun C, Kang YB. Formulation and delivery of itraconazole to the brain using a nanolipid carrier system. Int J Nanomedicine. 2014;9: 2117-26.

108. Kaur IP, Bhandari R, Bhandari S, Kakkar V. Potential of solid lipid nanoparticles in brain targeting. J Control Release. 2008;127(2):97-109.

\section{PICTORIAL ABSTRACT}

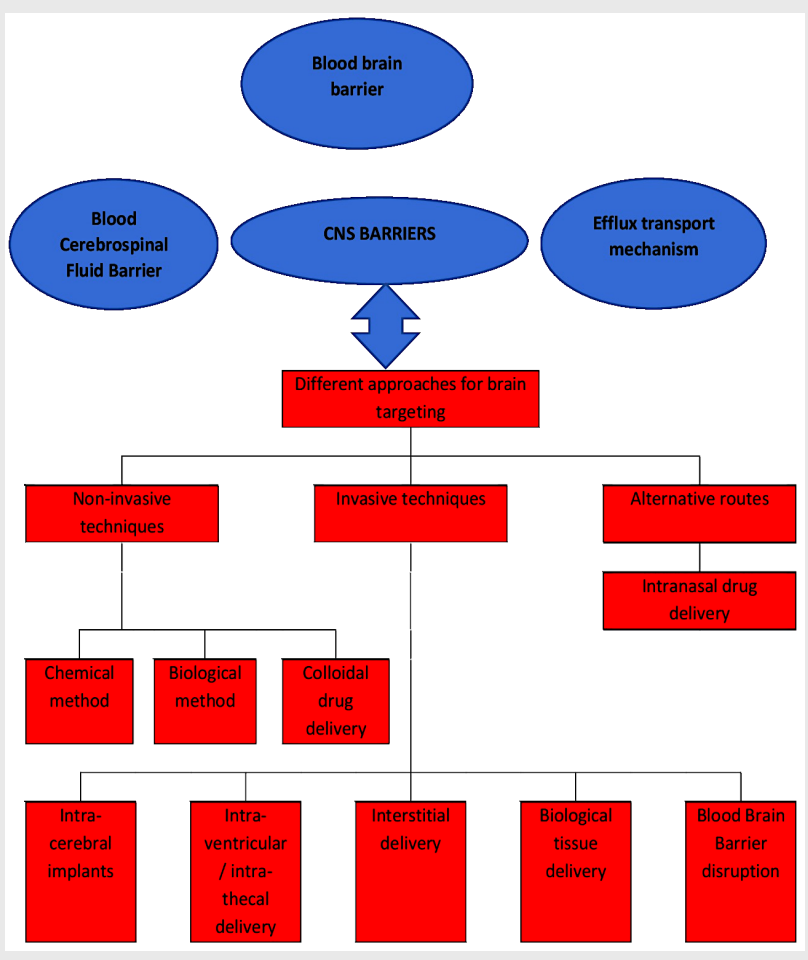

\section{SUMMARY}

- Delivery of drug to CNS has been challenging for formulating researchers even with continuous development in the field of pharmaceutical sciences.

- This review article basically focuses on the various infectious diseases of CNS and the problems and challenges associated with drug development for such infectious diseases of CNS.

- Various anatomical and physiological barriers of brain which protect the brain also render drugs ineffective by preventing passage of sufficient amount of drug molecules.

- The advent and application of different invasive and non-invasive techniques are proving to be effective in improving drug delivery to the brain. Nano technology in particular has been extensively applied for development and formulation of lipid nanoparticle dosages form.

Cite this article: Padhi S, Mazumder R, Bisth S. Development and Application of Lipid Nanotechnology on Infectious Diseases of CNS- Current Scenario. Indian J of Pharmaceutical Education and Research. 2019;53(3):355-65. 